\title{
Increased Serum Immunoglobulin Responses to Gut Commensal Gram- Negative Bacteria in Unipolar Major Depression and Bipolar Disorder Type 1, Especially When Melancholia is Present
}

(1) Denitsa Simeonova, M.D.; (1) Drozdstoy Stoyanov, M.D., Ph.D.; (2) Jean-Claude Leunis, Ph.D.; (3,4), Andre F. Carvalho, M.D., Ph.D.; (5) Marta Kubera, Ph.D.; (6,7) Marianna Murdjeva, M.D., Ph.D.; $(1,8,9)$ Michael Maes, M.D., Ph.D.

1. Department of Psychiatry and Medical Psychology, Medical Faculty, Medical University of Plovdiv, Plovdiv, Bulgaria;

2. Monnet Research Center, Louvain-La-Neuve, Belgium;

3. Centre for Addiction and Mental Health (CAMH), Toronto, ON, Canada;

4. Department of Psychiatry, University of Toronto, Toronto, ON, Canada;

5. Department of Experimental Neuroendocrinology, Maj Institute of Pharmacology, Polish Academy of Sciences, Krakow, Poland;

6. Department of Microbiology and Immunology, Faculty of Pharmacy, Medical University of Plovdiv, Plovdiv, Bulgaria;

7. Section of Immunological Assessment of Chronic Stress, Technological Center of Emergency Medicine, Plovdiv;

8. Department of Psychiatry, Faculty of Medicine, Chulalongkorn University, Bangkok, Thailand; 9. Impact Research Center, Deakin University, Geelong, Australia. 
Corresponding author:

Prof. Dr. Michael Maes, M.D., Ph.D.

Department of Psychiatry

Medical University of Plovdiv

Plovdiv

Bulgaria

dr.michaelmaes@hotmail.com

https://scholar.google.co.th/citations?user=1wzMZ7UAAAAJ\&hl=th\&oi=ao

denitsa.simeonova.bg@gmail.com

stojanovpisevski@gmail.com

jleunis@ @otmail.com

Andre.Carvalho@camh.ca

kubera@if-pan.krakow.pl

mmurdjeva@yahoo.com

dr.michaelmaes@hotmail.com 
Abstract

Major depression (MDD) is accompanied by higher serum $\operatorname{IgM} / \operatorname{Ig}$ A responses to LPS of Gram-negative bacteria, suggesting increased bacterial translocation and gut dysbiosis. Gut dysbiosis may occur in bipolar disorder (BD) and there are differences between MDD and BD type 1 (BP1) and -2 (BP2) in nitro-oxidative stress biomarkers associated with leaky gut. This study examines serum IgM/IgA responses directed to LPS of 6 Gram-negative bacteria in $29 \mathrm{BP} 1,37$ BP2, $44 \mathrm{MDD}$ and 30 healthy individuals. MDD plus BD was best discriminated from controls by increased $\operatorname{IgM} / \operatorname{Ig}$ A responses to Pseudomonas aeruginosa. BP1 patients showed higher IgM responses to Morganella morganii as compared with MDD and BP2 patients. Patients with melancholia showed higher IgA responses to Citrobacter koseri as compared to controls and nonmelancholic depression. The total score on the Hamilton Depression Rating Scale was significantly associated with IgA responses, especially C. koseri. IgG responses to oxidized low-density lipoprotein were significantly associated with signs of increased bacterial translocation. In conclusion, not only MDD but also BP1 and BP2 are accompanied by an immune response due to the increased load of plasma LPS of gut commensal bacteria while these aberrations in the gutbrain axis are most pronounced in BP1 and patients with melancholic features. Activated oxidative stress pathways and autoimmune responses to oxidative specific epitopes in mood disorders may be driven by a breakdown in gut paracellular, transcellular and/or vascular pathways. If replicated, drugs that protect the integrity of the gut barrier may offer novel therapeutic opportunities for BP1 and MDD. 
Keywords: depression, bipolar disorder, gut, bacterial translocation, LPS, oxidative stress, neuroimmune, immunology, psychiatry 


\section{Introduction}

Recent studies in major depressive disorder (MDD), bipolar disorder (BD) type 2 (BP2) and type 1 (BP1) show evidence that these disorders are associated with a) activated immune pathways; b) mild chronic inflammation (Anderson \& Maes, 2015; McNamara \& Lotrich, 2012; Rosenblat, Cha, Mansur, \& McIntyre, 2014; Slyepchenko et al., 2017); and c) activated neurooxidative and neuro-nitrosative stress pathways (Michael Maes, Galecki, Chang, \& Berk, 2011). A recent meta-analysis in MDD and BD shows lowered levels of key antioxidants and total antioxidant capacity and overall disruption of oxidative stress pathways in patients with MDD versus healthy controls (Liu et al., 2015). MDD and BP1 patients may show increased oxidative and nitrosative stress as compared to controls and BP2 patients while the latter group does not appear to differ from controls (Maes et al., 2019a; 2019b).

A possible pathway that may underpin these three interrelated pathophysiological phenomena (Berk et al., 2013; Steven Moylan et al., 2014) is an increased translocation of Gramnegative gut commensal bacteria. In 2008, it was reported that systemic $\operatorname{IgM}$ and $\operatorname{IgA-mediated}$ immune responses to endotoxins (LPS) of gut commensal bacteria are significantly increased in patients with MDD when compared to controls (Maes et al., 2008). These findings suggest that a) there is an increased translocation of LPS of Gram-negative bacteria including Hafnia alvei, Pseudomonas aeruginosa, Morganella morganii, Pseudomonas putida, Citrobacter koseri, and Klebsiella pneumoniae, and b) increased gut dysbiosis are involved in the pathophysiology of MDD (Maes et al., 2008; Simeonova et al., 2018). In physiological conditions, the gastrointestinal wall provides a geographical barrier (gut-wall barrier) that sequesters Gram-negative bacteria in the gut lumen from the peripheral blood circulation (Bested et al., 2013; Vojdani \& Vojdani, 2019). This gut barrier comprises different components including the paracellular pathway with tight and 
adherens junctions, the transcellular pathway and the vascular pathway (Maes et al., 2019c; Simeonova et al., 2018; Vojdani and Vojdani, 2019). Nevertheless, various pathophysiological conditions are accompanied by a breakdown of one or more components of this barrier thereby allowing increased translocation of LPS or Gram-negative bacteria into the mesenteric lymph nodes and beyond into the blood circulation (Maes et al., 2008; 2012a; 2019c; 2019a; Morris et al., 2016; Simeonova et al., 2018; Slyepchenko et al., 2017). Once translocated into the lymph nodes or beyond, $\operatorname{Ig} \mathrm{A}$ and $\operatorname{IgM}$ responses to the LPS and other antigens of Gram-negative bacteria may be mounted (Maes et al., 2008). Moreover, pathogen-associated molecular patterns (PAMPs) including LPS of Gram-negative bacteria may activate the Toll-Like Receptor (TLR)-4 complex which causes downstream activation of immune-inflammatory and oxidative stress pathways as indicated by increased levels of pro-inflammatory cytokines and reactive oxygen species including peroxides and nitric oxide (Lucas \& Maes, 2013; Lucas et al., 2015). As such, LPS or bacterial translocation may cause immune, inflammatory and oxidative stress responses. Furthermore, injection of even minimal amounts of LPS to human volunteers may decrease mood and induce anxiety (Eisenberger et al., 2010; Grigoleit et al., 2011), while, in animal models, repeated administration of LPS induces depressive-like behaviors as well as neuro-inflammatory responses (Kubera et al., 2013; Rodrigues et al., 2018). There are now also data that alterations in microbial composition in the gut, indicating gut dysbiosis, may occur in psychiatric disorders including MDD (Aizawa et al., 2016; Jiang et al., 2015; Lin et al., 2017; Naseribafrouei et al., 2014) and BD (Nguyen et al., 2018). Finally, breakdown of the gut barrier, especially the paracellular and vascular pathways may cause increased gut permeability (leaky gut) thereby inducing increased bacterial or LPS translocation and consequently increased IgM/IgA-mediated immune responses against Gram-negative gut commensal bacteria (Maes et al., 2008; 2019c). 
However, it remains unknown whether $\operatorname{Ig} \mathrm{A} / \mathrm{IgM}$ responses to Gram-negative bacteria are also increased in $\mathrm{BD}$ patients during an acute depressive episode and whether there are differences between BP1 and BP2 patients. Hence, the current study was conducted to assess the IgM and IgA responses to LPS of $H$. alvei, $P$. aeruginosa, M. morganii, $P$. putida, C. koseri, and $K$. pneumoniae in patients with BP1 and BP2, versus MDD and healthy controls. The specific hypotheses are that $\mathrm{BD}$ and MDD patients show increased $\operatorname{IgM} / \operatorname{IgA}$ responses to these Gram-negative bacteria as compared with controls.

\section{Subjects and Methods}

\section{Subjects}

One hundred and forty participants took part in the study and they were categorized in the following groups: BP1 ( $n=29)$; BP2 ( $=37)$; MDD $(n=44)$; and healthy controls $(n=30)$. Patients with BP depression and MDD were recruited at the clinics of the last author in Belgium, while healthy controls consisted of family members, friends and employees of the clinics and affiliated institutions. The enrolled subjects were between 18 and 71 years of age, male and female, of Caucasian descent. The socio-economic status of all participants was comparable between subjects, namely middle-higher class in a country with minor differences between classes. Diagnoses of BP1, BP2, and MDD were made using the criteria of the DSM-IV-TR (First et al., 2002) using the structured clinical interview for the DSM-IV. We additionally measured the severity of illness using the Hamilton Depression Rating Scale (HAM-D) (Hamilton, 1960) and only patients in an acute depressive episode were included while we used a score above 15 on the HAM-D instrument as an inclusion criterion. The presence of "melancholia" was defined based on the DSM-IV-TR criteria across MDD, BP1, and BP2 and, as such, we included 27 melancholia 
patients, namely 4 with BP2, 8 with BP1 and 15 with MDD. Exclusion criteria for controls and patients are a) neuro-inflammatory disease including Alzheimer's disease, Parkinson's disorder, multiple sclerosis and stroke; b) (auto)immune disorders including type 1 diabetes, COPD, chronic kidney disease, rheumatoid arthritis or inflammatory bowel disease; and c) allergic conditions 2 months prior to the study; c) subjects who had a lifetime history of using immunomodulatory drugs (such as glucocorticoids) and subjects who used therapeutic dosages of omega-3 polyunsaturated fatty acids of antioxidants; and d) subjects with a body mass index (BMI) above 30. Patients were excluded when they had suffered from another axis-1 psychiatric disorder, except for MDD and $\mathrm{BP}$, and from chronic MDD (that is $>2$ year). Controls were excluded for any lifetime or current diagnosis of axis-1 psychiatric disorders. The study has been approved by the ethical committee of the Medical University of Plovdiv (2/19.04.2018). All subjects gave written informed consent after the study has been explained to them and before their enrolment into the study.

\section{Materials and methods}

Fasting peripheral blood was sampled from all subjects in the morning hours (8.00 -10.00 a.m.) and collected serum was frozen at $-80^{\circ} \mathrm{C}$ until thawed for assay of $\operatorname{IgA}$ and $\operatorname{IgM}$ directed against the LPS of Gram-negative bacteria including $H$. alvei, $P$. aeruginosa, M. morganii, $P$. putida, C. koseri, and K. pneumoniae. A description of the measurements of $\operatorname{Ig} \mathrm{A} / \operatorname{IgM}$ antibodies directed to LPS of those Gram-negative bacteria is given somewhere else in detail (Geffard et al., 2002; Maes et al., 2008). The inter-assay coefficients of variation ) CV( were $<10 \%$. The assays of IgG responses to oxidized LDL and peroxides have been described previously (Maes et al., 2010). IgG to oxLDL was measured by means of an enzyme immunoassay (EIA; Biomedica Medizinproducte $\mathrm{GmbH} \& \mathrm{Co}$; A-1210 Wien, Austria; Cat. no: BI-20032; 12 x 8 tests; 
conventional 96-well ELISA format). The standard range is $37-1200 \mathrm{mU} / \mathrm{ml}$, the detection limit of the assay is $48 \mathrm{mU} / \mathrm{ml}$ and the inter-assay coefficient of variation $4.0 \%$. Peroxides were determined using a colorimetric assay Oxystat (Biomedica Medizinproducte GmBH \& Co KG, A1210 Wien) for the quantitative determination of peroxides in EDTA plasma (Cat No BI-5007). The detection limit of the assay is $7 \mu \mathrm{mol} / \mathrm{l}$ and the interassay $\mathrm{CV}$ is $5.1 \%$.

\section{Statistics}

We used analysis of contingency tables (Chi-square test) to assess associations between categorical variables and analysis of variance (ANOVAs) to assess differences in continuous variables between groups. Correlations among variables were checked with Spearman's rank-order correlation analyses and Pearson's product-moment correlation coefficients. Multiple regression analysis was performed to assess the significant predictors (including the $\operatorname{IgM} / \operatorname{IgA}$ responses) of scale variables (including the severity of illness and oxidative stress variables). Multivariate GLM analysis was employed to assess the effects of diagnosis as explanatory variables (three groups: controls, and depression with and without melancholic features; and four groups: controls, BP1, $\mathrm{BP} 2$ and MDD) on the IgM and IgA responses to Gram-negative bacteria (dependent variables) while adjusting for background variables such as age and sex. Consequently, we performed tests for between-subject effects to check effects of diagnosis on all $\operatorname{IgM}$ and $\operatorname{IgA}$ responses separately and employed protected pairwise posthoc tests to assess pairwise differences between the diagnostic groups. Binary and multinomial logistic regression analysis was used to assess the best predictors of diagnostic classes and computed Odds ratios with $95 \%$ confidence intervals. OD values of the $\operatorname{IgM}$ and $\operatorname{Ig}$ A responses were first Ln transformed (to normalize the data distribution) and then processed in $\mathrm{z}$ transformation. We also computed an integrated index of bacterial 
translocation as $\mathrm{z}$ (sum of $\mathrm{z}$ values of $\operatorname{Ln} \operatorname{IgM}$ to the 6 Gram-negative bacteria + sum of $\mathrm{z}$ values of $\operatorname{Ln}$ IgA to the 6 Gram-negative bacteria). All statistical tests were two-tailed and a p-value of 0.05 was used for statistical significance. All statistical analyses were performed using Statistica 12, Stata SE-64, and IBM SPSS windows version 25.

\section{Results}

Socio-demographic data

Table 1 shows the socio-demographic data of the participants divided into 4 study groups (controls, MDD, BP1, and BP2). There were no significant differences in age, sex ratio, BMI between the 4 study groups. There were somewhat more subjects with TUD in the BP2 patient group than in normal control. Significantly more patients with melancholia were found in BP1 than in MDD and significantly more patients with treatment-resistant depression in MDD were detected than in BP2. There were no significant differences in severity of illness and number of episodes between the three patient subgroups. This table also shows the mean values of IgG against oxidized LDL and peroxide levels in the 4 groups. IgG to oxidized LDL was significantly greater in BP1 and MDD patients as compared with controls and higher in MDD than in BP2 patients. There were no significant differences in IgG to oxidized LDL between BP1 and BP2 patients. There was a trend towards higher peroxide levels in MDD as compared with controls.

\section{Differences in IgA responses to LPS between diagnostic groups.}

Table 2 shows the results of multivariate GLM analyses with IgA responses to Gramnegative bacteria as dependent variables and diagnoses as explanatory variables while adjusting for age and sex. Multivariate GLM analysis \#1 shows a significant effect of BP1/BP2/MDD on 
the IgA responses although with a small effect size (0.074). These diagnoses were associated with all 6 IgA responses to Gram-negative bacteria, except with $P$. aeruginosa and all analyses showed a small effect size (0.058-0.077). Multivariate GLM analysis \#2 shows a significant effect of melancholia on the $\operatorname{IgA}$ responses with a greater effect size of 0.165 . There were significant effects of this diagnosis on all six IgA values directed against Gram-negative bacteria, with the highest effect size for $C$. koseri followed by $K$. pneumoniae. There were no significant effects of age $(\mathrm{F}=1.47, \mathrm{df}=6 / 129, \mathrm{p}=0.428)$ and $\operatorname{sex}(\mathrm{F}=1.00, \mathrm{df}=6 / 129, \mathrm{p}=0.428)$ on the $6 \mathrm{IgA}$ values. In addition, we could not find any significant effects of treatment-resistant depression $(\mathrm{F}=1.70, \mathrm{df}=12 / 262$, $\mathrm{p}=0.066)$, nicotine dependence $(\mathrm{F}=0.79, \mathrm{df}=6 / 123, \mathrm{p}=0.274), \mathrm{BMI}(\mathrm{F}=0.49, \mathrm{df}=6 / 64, \mathrm{p}=0.815)$, use of mood stabilizers $(\mathrm{F}=1.56, \mathrm{df}=6 / 126, \mathrm{p}=0.165)$ or antidepressants $(\mathrm{F}=0.85, \mathrm{df}=6 / 126$, $\mathrm{p}=0.531)$.

Table 3 shows the estimated marginal mean values (in $\mathrm{z}$ scores) of the IgA responses to Gram-negative bacteria after adjusting for sex and age. IgA responses to $H$. alvei and $M$. morganii were significantly higher in BP1 and MDD than in controls. IgA responses to $P$. aeruginosa were significantly higher in all patient groups than in controls. IgA responses to P. putida and C. koseri were significantly higher in BP1 than in MDD and BP2 patients and controls. IgA responses to $K$. pneumoniae are significantly higher in BP1 than in controls. This table shows also the differences between controls and non-melancholic and melancholic patients. IgA responses to $H$. alvei were significantly higher in both depressed groups than in controls. IgA responses to $P$. aeruginosa were significantly higher in non-melancholic patients than controls. IgA responses to M. morganii, $P$. putida, C. koseri, and K. pneumoniae were higher in melancholia than in controls while those with non-melancholic depression occupied an intermediate position. 
Differences in IgM responses to LPS between diagnostic groups.

Table 4 displays the results of a multivariate GLM analysis with IgM responses to Gramnegative bacteria as dependent variables and diagnoses as explanatory variables while adjusting for age and sex. GLM analysis \#1 shows a significant effect of BP1/BP2/MDD on the IgM responses with an effect size of 0.121 . There was a significant impact of the diagnosis on all IgM values, except IgM to K. pneumoniae. The effect sizes were largest for M. morganii and P. putida. Table 3 shows the estimated marginal mean values (in $\mathrm{z}$ scores) of the IgM responses after adjusting for sex and age. IgM responses to $H$. alvei were significantly higher in BP1 and MDD than in controls and BP2. IgM responses to $P$. aeruginosa and $P$. putida were significantly higher in all patient groups as compared with controls. IgM responses to M. morganii and C. koseri and the integrated index of $\operatorname{IgM} / \operatorname{IgA}$ to all bacteria were significantly higher in BP1 than in BP2 and controls and higher in MDD than in controls. IgM to K. pneumoniae was higher in BP1 than in controls.

GLM analysis \#2 shows that there was a significant effect of the diagnosis melancholia versus non-melancholia or controls on the IgM values, although the effect size was only 0.089 . There were significant effects of this diagnosis on the IgM responses, except $C$. koseri and $K$. pneumoniae. Table 3 displays the differences between controls and patients with and without melancholia. IgM responses to $H$. alvei were significantly higher in the non-melancholia group as compared with controls. The other IgM responses were greater in the two depressed subgroups than in controls. The overall index of increased $\operatorname{IgM} / \operatorname{IgA}$ responses to all 6 bacteria was significantly different between the three groups and increased from controls $\rightarrow$ non-melancholic depression in $\mathrm{MDD} / \mathrm{BD} \rightarrow$ melancholic depression in $\mathrm{MDD} / \mathrm{BD}$. 
Multivariate GLM analysis \#2 shows that there were no significant effects of age $(\mathrm{F}=1.85$, $\mathrm{df}=6 / 129, \mathrm{p}=0.094)$ and $\operatorname{sex}(\mathrm{F}=1.57, \mathrm{df}=6 / 129, \mathrm{p}=0.160)$ on the $\mathrm{IgM}$ responses directed to Gramnegative bacteria. In addition, there were no significant effects of nicotine dependence $(\mathrm{F}=0.92$, $\mathrm{df}=6 / 123, \mathrm{p}=0.485), \mathrm{BMI}(\mathrm{F}=0.75, \mathrm{df}=6 / 64, \mathrm{p}=0.612)$, use of $\operatorname{mood}$ stabilizers $(\mathrm{F}=1.18, \mathrm{df}=6 / 126$, $\mathrm{p}=0.323)$ or antidepressants $(\mathrm{F}=2.07, \mathrm{df}=6 / 126, \mathrm{p}=0.061)$. Pairwise comparisons showed that there were no significant differences in any of the $6 \mathrm{IgM}$ values between patients with and without treatment resistant depression.

Best prediction of diagnoses using IgM/IgA responses.

Table 5 shows the results of binary and multinomial logistic regression analysis with diagnosis as dependent variables. Binary regression analysis discriminating mood disorders (MDD plus BD) from controls showed that mood disorders were best predicted $(\chi 2=28.60, \mathrm{df}=2, \mathrm{p}<0.001)$ by both IgA and IgM to P. aeruginosa with a Nagelkerke value of 0.286 . Multinomial regression \#2 shows the discrimination of controls, BP1, BP2 and MDD using the $6 \operatorname{IgM}$ and $6 \operatorname{Ig}$ A responses. We found that $\operatorname{IgM}$ to $M$. morganii $(\chi 2=18.60, \mathrm{df}=3, \mathrm{p}<0.001), \operatorname{IgA}$ to $M$. morganii $(\chi 2=14.61$, $\mathrm{df}=3, \mathrm{p}=0.002), \operatorname{IgM}$ to $P$. aeruginosa $(\chi 2=11.85, \mathrm{df}=3, \mathrm{p}=0.008)$ and age $(\chi 2=9.28, \mathrm{df}=3, \mathrm{p}=0.026)$ significantly $(\chi 2=54.35, \mathrm{df}=12, \mathrm{p}<0.001)$ discriminated the 4 groups with a Nagelkerke value of 0.344. Table 5 shows that BP2 and MDD were discriminated from controls by IgA to M. morganii and IgM to $P$. aeruginosa. BP1 was best discriminated from controls by IgA to $M$. morganii. BP1 was best discriminated from BP2 and MDD by $\operatorname{IgM}$ to M. morganii.

The second multinomial logistic regression in Table 5 examines the discrimination between controls, and patients with and without melancholic depression. We found that IgM to C. koseri $(\chi 2=23.15, \mathrm{df}=2, \mathrm{p}<0.001), \operatorname{IgA}$ to $P$. aeruginosa $(\chi 2=11.97, \mathrm{df}=23, \mathrm{p}=0.003)$, and $\operatorname{IgM}$ to $P$. 
aeruginosa $(\chi 2=16.14, \mathrm{df}=2, \mathrm{p}<0.001)$ significantly $(\chi 2=50.46, \mathrm{df}=6, \mathrm{p}<0.001)$ discriminated those 3 groups with a Nagelkerke value of 0.375 . IgA to C. koseri best predicted melancholia versus controls and non-melancholia, while both IgA and IgM to P. aeruginosa predicted nonmelancholic depression versus controls.

Prediction of severity of illness and oxidative biomarkers.

Table 6 shows three different multiple regression analyses. The first shows that $23.9 \%$ of the variance in the HAM-D score was explained by IgA to C. koseri and age combined. Pearson's correlation analyses showed that HAM-D values was significantly associated with IgA directed against $C$. koseri $(\mathrm{r}=0.447, \mathrm{p}<0.001, \mathrm{n}=110)$, K. pneumoniae $(\mathrm{r}=0.350, \mathrm{p}<0.001)$, M. morganii $(\mathrm{r}=0.305 \mathrm{p}=0.001)$, H.alvei $(\mathrm{r}=254, \mathrm{p}=0.007), P$. putida $(\mathrm{r}=0.244, \mathrm{p}=0.010)$ and $P$. aeruginosa $(\mathrm{r}=0.194, \mathrm{p}=0.042)$. IgG levels directed against oxidized LDL were best predicted $(18.9 \%$ of the variance) by $\operatorname{IgM}$ to $P$. aeruginosa and $\operatorname{IgA} H$. alvei. We found that $32.6 \%$ of the variance in peroxide levels was associated with sex and IgM to $P$. aeruginosa. There were no significant associations between any of the IgM values and the HAM-D total score.

\section{Discussion}

The first major finding of this study is that a) $\operatorname{IgA} / \operatorname{IgM}$ responses to the LPS of gut commensal bacteria were positively associated with mood disorders (MDD and BD combined) as compared to healthy controls; b) IgA/IgM responses were higher in MDD and BP1 than in controls, while BP2 occupied an intermediate position; c) IgA responses to P. putida and $C$. koseri were higher in BP1 than in MDD, BP2, and controls; and d) IgM responses to H. alvei, M. morganii and C. koseri were higher in $\mathrm{BP} 1$ than in $\mathrm{BP} 2$ and controls. These findings extend those of previous 
studies which showed increased IgA/IgM responses to the LPS of Gram-negative bacteria in MDD (Maes et al., 2008; 2012a). As explained in the Introduction, these findings indicate increased gut dysbiosis and bacterial translocation of commensal gut bacteria through the gut wall, thus supporting the evidence that increased gut permeability is a characteristic of MDD (Maes et al., 2008; 2012a). Moreover, the results show that the same pathways play a role in BP1 depression and that patients with the latter type of depression may show more bacterial translocation than MDD patients. Recent research papers reported changes in the microbiome in MDD (Aizawa et al., 2016; Jiang et al., 2015; Lin et al., 2017; Naseribafrouei et al., 2014) and BD as well (Nguyen et al., 2018). There is also some evidence that increased gut permeability is associated with BP depression (Dickerson et al., 2017; Severance et al., 2010) and with chronic MDD (Maes et al., 2008; 2012a). For example, the IgM responses to LPS of Gram-negative bacteria were significantly increased in patients suffering from chronic depression (duration $>2$ years) when compared to patients with non-chronic depression and controls (Maes et al., 2012a). Nevertheless, patients with chronic MDD or BD were excluded from the present study.

The data of the current study add to the differentiation of MDD, BP1, and BP2. Previously it was observed that signs of protein oxidation as measured using advanced protein oxidation products (AOPPs) are significantly higher in BP1 and MDD patients than in BP2 patients and controls (Maes et al., 2019a) while superoxide dismutase (SOD1) and lipid peroxide markers including malondialdehyde (MDA) were higher in MDD than in BP1, which in turn showed higher values than BP2. Recently, we also detected significant differences in immune profiles between

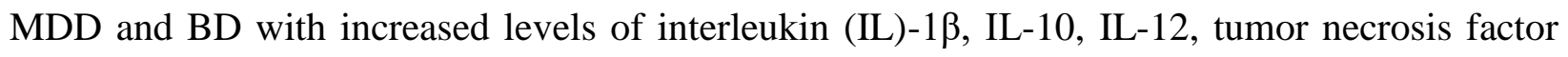
(TNF)- $\alpha$, and soluble TNF receptor (TNFR)-1 in MDD versus BD and increased IL-6, IL-18, IL33, sTNFR-2, ST2 (ILR Like 1) and KLOTHO in BD as compared with MDD (Brunoni et al., 
submitted). On the other hand, no significant differences in immune profiles (including IL-6, sIL$6 \mathrm{R}$, sIL-2R, acute-phase proteins) or oxidative stress (aldehyde formation) could be found between MDD and BD (Maes, 1995; Maes et al., 1997; Sowa-Kućma et al., 2018a). All in all, the current study as well previous studies indicate that the immune pathophysiology of MDD and BD and BP1 and BP2 may be different.

The second major finding of the study is that there are signs of increased bacterial translocation in patients with melancholia as compared with patients without melancholia and controls. To the best of our knowledge, this is the first study showing increased bacterial translocation in MDD/BD patients with melancholia. Previously, there were some reports that melancholia is accompanied by more pronounced aberrations in immune and oxidative stress pathways as compared with non-melancholic depression including increased levels of sIL-6R, aldehyde formation, and TNF- $\alpha$ signaling (Siwek et al., 2017; Sowa-Kućma et al., 2018b, 2018a). More specifically, in the current study, we found that the $\operatorname{IgA}$ (but not $\operatorname{IgM}$ ) responses to $M$. morganii, $P$. putida, C. koseri, and $K$. pneumoniae were significantly higher in MDD/BD patients with melancholia as compared with those without melancholia. Likewise, the HAM-A score was significantly associated with $\operatorname{IgA}$ (but not $\operatorname{IgM}$ ) responses to all 6 Gram-negative bacteria but most strongly with $C$. koseri. During immune responses, $\operatorname{IgM}$ antibodies are the first antibodies to be produced followed by IgA antibodies. Both natural or innate IgM (produced by B1 or primitive B cells) and adaptive IgM (produced by B2 B cells) antibodies play a key role in the host defence against pathogens, including intra-cellular bacteria, while natural $\operatorname{IgM}$ have additional antiinflammatory and anti-oxidative properties (Maes et al., 2019c; Racine \& Winslow, 2009). In this respect, it is interesting to note that natural B1 cells residing in the peritoneum contribute to the long-term maintenance of $\operatorname{IgM}$ levels and protection against bacterial infections (Racine \& 
Winslow, 2009). B1 cells in the lamina propria may undergo class-switching to IgA secretory cells leading to antibody diversification and more complete protection against pathogenic and commensal microorganisms (Cerutti, 2008; Cerutti \& Rescigno, 2008; Twigg, 2005). IgA antibodies play a key role in immune exclusion and immune protection and offer another layer of protection against intestinal bacteria including at mucosal surfaces (Cerutti, 2008). All in all, it appears that depression in patients with MDD/BD is associated with natural/adaptive $\operatorname{IgM}$ and $\operatorname{IgA}$ responses to Gram-negative bacteria, while melancholia is associated with $\operatorname{IgA}$ responses only. This could suggest that patients with BD and unipolar depression are at increased risk to develop melancholia when they show relatively lower IgM levels and thus a lowered protection. Future prospective research projects should further examine the role of $\operatorname{IgM}$ and $\operatorname{IgA}$ responses to microorganisms in both depression and melancholia.

The third major finding of this study is that indices of oxidative stress in MD/BD are predicted by increased bacterial translocation. Thus, IgM levels to P. aeruginosa and $H$. alvei predicted increased IgG-mediated autoimmune responses to oxidized LDL, while IgM to $P$. putida predicted increased peroxide levels. Such findings suggest that translocation of LPS or Gramnegative bacteria may not only drive immune responses but also activated oxidative stress pathways and autoimmune responses to oxidative specific epitopes in both MDD and BD. Importantly, we found that both MDD and BD are accompanied by higher IgG levels to oxidized LDL while the latter is also a characteristic of coronary artery disease (CAD) (Maes et al., 2010; 2011b). These associations are of particular interest because IgG levels to oxidized LDL are directly associated with the development of CAD while the latter condition is frequently comorbid with MDD and BD (Maes et al., 2010). As such, increased bacterial translocation in mood disorders may underpin at least in part the pathophysiology of CAD (Maes et al., 2011b). 
Epidemiological studies reported links between depressive symptoms and increased carotid artery intima-media thickness, a marker of accelerated vascular aging (Elovainio et al., 2005). A study on intrahepatic sinusoidal endothelial dysfunction after LPS administration showed increased dysfunction and oxidative stress (La Mura et al., 2014).

As described in the Introduction increased levels of LPS due to bacterial translocation may cause depressive-like behaviors (Maes et al., 2013; 2008). Recent studies also suggest that changes in the microbiome including dysbiosis may lead to behavioral and mood changes such as anxiety, exaggerated stress responses (Sudo et al., 2004), and reduced social motivation (Dinan \& Cryan, 2013). Administration of small amounts of LPS may result in depression and anxiety symptoms, impaired cognition and an increased sense of pain in viscera (Wegner et al., 2015). It is also possible that increased translocation of LPS may explain the development of melancholia symptoms. In this respect, animal models show that chronic and/or repeated administration of LPS may induce long-lasting changes in neuro-oxidative and neuro-immune pathways (similar as those detected in MDD) in association with anhedonia, a key symptom of melancholia (Kubera et al., 2013; Rodrigues et al., 2018). LPS may cause depressive-like or melancholia symptoms via different routes, including PAMP-activation of the TLR complex with consequent production of reactive oxygen and nitrogen species and pro-inflammatory cytokines leading to oxidative and nitrosative stress as well as activated immune-inflammatory pathways (Lucas \& Maes, 2013; Lucas et al., 2015). As reviewed previously, these are three intertwined pathways that underpin the pathophysiology of MDD and BD (Maes, 1995; Moylan et al., 2013; 2014).

The results of the present study should be discussed with respect to its limitations. First, this is a case-control study that does not allow making inferences on causal relationships. Second, different environmental factors that may change the microbiome were not controlled for including 
the type of diet and exercise. Thirdly, it would have been interesting if we had assayed immuneinflammatory biomarkers as well as the gut microbiome.

In conclusion, this study shows that not only MDD but also BP1 is accompanied by increased $\operatorname{IgM} / \operatorname{Ig} \mathrm{A}$ responses to gut commensal Gram-negative bacteria indicating increased bacterial translocation while some IgM responses to Gram-negative bacteria were even greater in BP1 than in MDD. BP2 patients show values that occupy an intermediate position between BP1/MDD and normal controls. Melancholic patients show highly increased IgA responses directed to Gram-negative bacteria, but lack the increase in IgM responses to the same bacteria. The humoral immune responses to Gram-negative bacteria are significantly associated with indices of oxidative stress indicating that leaky gut may drive oxidative stress and IgG-mediated autoimmune responses directed to oxidative specific epitopes. If replicated, drugs that protect the integrity of the gut barrier may offer novel therapeutic opportunities for BP1 and MDD.

\section{Conflict of interest}

The authors have no conflict of interest with any commercial or other association in connection with the submitted article.

\section{Funding}

There was no specific funding for this specific study. 
20

All the contributing authors have participated in the manuscript. MM performed the statistical analyses. J-C Leunis performed the assays. All authors contributed to the interpretation of the data and writing of the manuscript. All authors approved the final version of the manuscript.

\section{Ethical Approval}

All procedures performed in studies involving human participants were in accordance with the ethical standards of the ethical committee of the Medical University of Plovdiv (2/19.04.2018). and with the 1964 Helsinki declaration and its later amendments or comparable ethical standards.

\section{References}

Aizawa, E., Tsuji, H., Asahara, T., Takahashi, T., Teraishi, T., Yoshida, S., ... Kunugi, H. (2016). Possible association of Bifidobacterium and Lactobacillus in the gut microbiota of patients with major depressive disorder. Journal of Affective Disorders, 202, 254-257. https://doi.org/10.1016/j.jad.2016.05.038

Anderson, G., \& Maes, M. (2015). Bipolar Disorder: Role of Immune-Inflammatory Cytokines, Oxidative and Nitrosative Stress and Tryptophan Catabolites. Current Psychiatry Reports, 17(2), 8. https://doi.org/10.1007/s11920-014-0541-1

Berk, M., Williams, L. J., Jacka, F. N., O’Neil, A., Pasco, J. A., Moylan, S., ... Maes, M. (2013). So depression is an inflammatory disease, but where does the inflammation come from? BMC Medicine, 11(1), 200. https://doi.org/10.1186/1741-7015-11-200

Bested, A. C., Logan, A. C., \& Selhub, E. M. (2013). Intestinal microbiota, probiotics and mental health: from Metchnikoff to modern advances: Part II - contemporary contextual research. Gut Pathogens, 5(1), 3. https://doi.org/10.1186/1757-4749-5-3 
Cerutti, A. (2008). Location, location, location: B-cell differentiation in the gut lamina propria. Mucosal Immunology, 1(1), 8-10. https://doi.org/10.1038/mi.2007.8

Cerutti, A., \& Rescigno, M. (2008). The Biology of Intestinal Immunoglobulin A Responses. Immunity, 28(6), 740-750. https://doi.org/10.1016/j.immuni.2008.05.001

Dickerson, F., Severance, E., \& Yolken, R. (2017). The microbiome, immunity, and schizophrenia and bipolar disorder. Brain, Behavior, and Immunity, 62, 46-52. https://doi.org/10.1016/j.bbi.2016.12.010

Dinan, T. G., \& Cryan, J. F. (2013). Melancholic microbes: a link between gut microbiota and depression? Neurogastroenterology \& Motility, 25(9), 713-719. https://doi.org/10.1111/nmo.12198

Eisenberger, N. I., Berkman, E. T., Inagaki, T. K., Rameson, L. T., Mashal, N. M., \& Irwin, M. R. (2010). Inflammation-induced anhedonia: endotoxin reduces ventral striatum responses to reward. Biological Psychiatry, 68(8), 748-754. https://doi.org/10.1016/j.biopsych.2010.06.010

Elovainio, M., Keltikangas-Järvinen, L., Kivimäki, M., Pulkki, L., Puttonen, S., Heponiemi, T., ... Raitakari, O. T. (2005). Depressive symptoms and carotid artery intima-media thickness in young adults: the Cardiovascular Risk in Young Finns Study. Psychosomatic Medicine, 67(4), 561-567. https://doi.org/10.1097/01.psy.0000170340.74035.23

First, M. B., Frances, A., \& Pincus, H. A. (Eds.). (2002). DSM-IV-TR Handbook of Differential Diagnosis (Vol. 1). Arlington, VA: American Psychiatric Publishing, Inc. https://doi.org/10.1176/appi.books.9781585622658

Geffard, M., Bodet, D., Martinet, Y., \& Dabadie, M.-P. (2002). Intérêt de l'évaluation d'IgM et d'IgA spécifiques circulant dans le serum de malades atteints de sclérose en plaques (SEP). 
Immuno-Analyse \& Biologie Spécialisée, 17(5), 302-310. https://doi.org/10.1016/S09232532(02)01214-0

Grigoleit, J.-S., Kullmann, J. S., Wolf, O. T., Hammes, F., Wegner, A., Jablonowski, S., ...

Schedlowski, M. (2011). Dose-dependent effects of endotoxin on neurobehavioral functions in humans. PloS One, 6(12), e28330. https://doi.org/10.1371/journal.pone.0028330

Hamilton, M. (1960). A RATING SCALE FOR DEPRESSION. Journal of Neurology, Neurosurgery \& Psychiatry, 23(1), 56-62. https://doi.org/10.1136/jnnp.23.1.56

Jiang, H., Ling, Z., Zhang, Y., Mao, H., Ma, Z., Yin, Y., ... Ruan, B. (2015). Altered fecal microbiota composition in patients with major depressive disorder. Brain, Behavior, and Immunity, 48, 186-194. https://doi.org/10.1016/j.bbi.2015.03.016

Kubera, M., Curzytek, K., Duda, W., Leskiewicz, M., Basta-Kaim, A., Budziszewska, B., ... Maes, M. (2013). A new animal model of (chronic) depression induced by repeated and intermittent lipopolysaccharide administration for 4months. Brain, Behavior, and Immunity, 31, 96-104. https://doi.org/10.1016/j.bbi.2013.01.001

La Mura, V., Pasarín, M., Rodriguez-Vilarrupla, A., García-Pagán, J. C., Bosch, J., \& Abraldes, J. G. (2014). Liver sinusoidal endothelial dysfunction after LPS administration: A role for inducible-nitric oxide synthase. Journal of Hepatology, 61(6), 1321-1327. https://doi.org/10.1016/j.jhep.2014.07.014

Lin, P., Ding, B., Feng, C., Yin, S., Zhang, T., Qi, X., ... Li, Q. (2017). Prevotella and Klebsiella proportions in fecal microbial communities are potential characteristic parameters for patients with major depressive disorder. Journal of Affective Disorders, 207, 300-304. https://doi.org/10.1016/j.jad.2016.09.051

Liu, T., Zhong, S., Liao, X., Chen, J., He, T., Lai, S., \& Jia, Y. (2015). A Meta-Analysis of 
Oxidative Stress Markers in Depression. PloS One, 10(10), e0138904. https://doi.org/10.1371/journal.pone.0138904

Lucas, K., \& Maes, M. (2013). Role of the Toll Like Receptor (TLR) Radical Cycle in Chronic Inflammation: Possible Treatments Targeting the TLR4 Pathway. Molecular Neurobiology, 48(1), 190-204. https://doi.org/10.1007/s12035-013-8425-7

Lucas, K., Morris, G., Anderson, G., \& Maes, M. (2015). The Toll-Like Receptor Radical Cycle Pathway: A New Drug Target in Immune-Related Chronic Fatigue. CNS \& Neurological Disorders - Drug Targets, 14(7), 838-854.

https://doi.org/10.2174/1871527314666150317224645

Maes, M. (1995). Evidence for an immune response in major depression: a review and hypothesis. Progress in Neuro-Psychopharmacology \& Biological Psychiatry, 19(1), 1138. Retrieved from http://www.ncbi.nlm.nih.gov/pubmed/7708925

Maes, M, Delange, J., Ranjan, R., Meltzer, H. Y., Desnyder, R., Cooremans, W., \& Scharpé, S. (1997). Acute phase proteins in schizophrenia, mania and major depression: modulation by psychotropic drugs. Psychiatry Research, 66(1), 1-11. Retrieved from http://www.ncbi.nlm.nih.gov/pubmed/9061799

Maes, Michael, Kubera, M., \& Leunis, J.-C. (2008). The gut-brain barrier in major depression: intestinal mucosal dysfunction with an increased translocation of LPS from gram negative enterobacteria (leaky gut) plays a role in the inflammatory pathophysiology of depression. Neuro Endocrinology Letters, 29(1), 117-124. Retrieved from http://www.ncbi.nlm.nih.gov/pubmed/18283240

Maes, Michael, Mihaylova, I., Kubera, M., Uytterhoeven, M., Vrydags, N., \& Bosmans, E. (2010). Increased plasma peroxides and serum oxidized low density lipoprotein antibodies 
in major depression: Markers that further explain the higher incidence of neurodegeneration and coronary artery disease. Journal of Affective Disorders, 125(1-3), 287-294. https://doi.org/10.1016/j.jad.2009.12.014

Maes, Michael, Galecki, P., Chang, Y. S., \& Berk, M. (2011a). A review on the oxidative and nitrosative stress (O\&amp;NS) pathways in major depression and their possible contribution to the (neuro)degenerative processes in that illness. Progress in NeuroPsychopharmacology and Biological Psychiatry, 35(3), 676-692. https://doi.org/10.1016/j.pnpbp.2010.05.004

Maes, Michael, Ruckoanich, P., Chang, Y. S., Mahanonda, N., \& Berk, M. (2011b). Multiple aberrations in shared inflammatory and oxidative \&amp; nitrosative stress (IO\&amp;NS) pathways explain the co-association of depression and cardiovascular disorder (CVD), and the increased risk for CVD and due mortality in depressed patients. Progress in NeuroPsychopharmacology \& Biological Psychiatry, 35(3), 769-783. https://doi.org/10.1016/j.pnpbp.2010.06.008

Maes, Michael, Kubera, M., Leunis, J.-C., \& Berk, M. (2012a). Increased IgA and IgM responses against gut commensals in chronic depression: Further evidence for increased bacterial translocation or leaky gut. Journal of Affective Disorders, 141(1), 55-62. https://doi.org/10.1016/j.jad.2012.02.023

Maes, Michael, Twisk, F. N. M., Kubera, M., Ringel, K., Leunis, J.-C., \& Geffard, M. (2012b). Increased IgA responses to the LPS of commensal bacteria is associated with inflammation and activation of cell-mediated immunity in chronic fatigue syndrome. Journal of Affective Disorders, 136(3), 909-917. https://doi.org/10.1016/j.jad.2011.09.010

Maes, M., Kubera, M., Leunis, J.-C., Berk, M., Geffard, M., \& Bosmans, E. (2013). In 
depression, bacterial translocation may drive inflammatory responses, oxidative and nitrosative stress (O\&amp;NS), and autoimmune responses directed against O\&amp;NSdamaged neoepitopes. Acta Psychiatrica Scandinavica, 127(5), 344-354.

https://doi.org/10.1111/j.1600-0447.2012.01908.x

Maes, Michael, Landucci Bonifacio, K., Morelli, N. R., Vargas, H. O., Barbosa, D. S., Carvalho, A. F., \& Nunes, S. O. V. (2019a). Major Differences in Neurooxidative and Neuronitrosative Stress Pathways Between Major Depressive Disorder and Types I and II Bipolar Disorder. Molecular Neurobiology, 56(1), 141-156. https://doi.org/10.1007/s12035018-1051-7

Maes, Michael, Moraes, J. B., Congio, A., Bonifacio, K. L., Barbosa, D. S., Vargas, H. O., ... Nunes, S. O. V. (2019b). Development of a Novel Staging Model for Affective Disorders Using Partial Least Squares Bootstrapping: Effects of Lipid-Associated Antioxidant Defenses and Neuro-Oxidative Stress. Molecular Neurobiology. https://doi.org/10.1007/s12035-019-1552-z

Maes, Michael, Sirivichayakul, S., Kanchanatawan, B., \& Vodjani, A. (2019c). Breakdown of the Paracellular Tight and Adherens Junctions in the Gut and Blood Brain Barrier and Damage to the Vascular Barrier in Patients with Deficit Schizophrenia. Neurotoxicity Research. https://doi.org/10.1007/s 12640-019-00054-6

McNamara, R. K., \& Lotrich, F. E. (2012). Elevated immune-inflammatory signaling in mood disorders: a new therapeutic target? Expert Review of Neurotherapeutics, 12(9), 1143-1161. https://doi.org/10.1586/ern.12.98

Morris, G., Berk, M., Carvalho, A., Caso, J., Sanz, Y., \& Maes, M. (2016). The Role of Microbiota and Intestinal Permeability in the Pathophysiology of Autoimmune and 
Neuroimmune Processes with an Emphasis on Inflammatory Bowel Disease Type 1

Diabetes and Chronic Fatigue Syndrome. Current Pharmaceutical Design, 22(40), 60586075. https://doi.org/10.2174/1381612822666160914182822

Moylan, S, Maes, M., Wray, N. R., \& Berk, M. (2013). The neuroprogressive nature of major depressive disorder: pathways to disease evolution and resistance, and therapeutic implications. Molecular Psychiatry, 18(5), 595-606. https://doi.org/10.1038/mp.2012.33

Moylan, Steven, Berk, M., Dean, O. M., Samuni, Y., Williams, L. J., O’Neil, A., ... Maes, M. (2014). Oxidative \&amp; nitrosative stress in depression: Why so much stress?

Neuroscience \& Biobehavioral Reviews, 45, 46-62.

https://doi.org/10.1016/j.neubiorev.2014.05.007

Naseribafrouei, A., Hestad, K., Avershina, E., Sekelja, M., Linløkken, A., Wilson, R., \& Rudi, K. (2014). Correlation between the human fecal microbiota and depression.

Neurogastroenterology \& Motility, 26(8), 1155-1162. https://doi.org/10.1111/nmo.12378

Nguyen, T. T., Kosciolek, T., Eyler, L. T., Knight, R., \& Jeste, D. V. (2018). Overview and

Systematic Review of Studies of Microbiome in Schizophrenia and Bipolar Disorder HHS

Public Access. J Psychiatr Res, 99, 50-61. https://doi.org/10.1016/j.jpsychires.2018.01.013

Racine, R., \& Winslow, G. M. (2009). IgM in microbial infections: taken for granted?

Immunology Letters, 125(2), 79-85. https://doi.org/10.1016/j.imlet.2009.06.003

Rodrigues, F. T. S., de Souza, M. R. M., Lima, C. N. de C., da Silva, F. E. R., Costa, D. V. da S., dos Santos, C. C., ... Macedo, D. (2018). Major depression model induced by repeated and intermittent lipopolysaccharide administration: Long-lasting behavioral, neuroimmune and neuroprogressive alterations. Journal of Psychiatric Research, 107, 57-67.

https://doi.org/10.1016/j.jpsychires.2018.10.003 
Rosenblat, J. D., Cha, D. S., Mansur, R. B., \& McIntyre, R. S. (2014). Inflamed moods: A review of the interactions between inflammation and mood disorders. Progress in NeuroPsychopharmacology and Biological Psychiatry, 53, 23-34.

https://doi.org/10.1016/J.PNPBP.2014.01.013

Severance, E. G., Dickerson, F. B., Halling, M., Krivogorsky, B., Haile, L., Yang, S., ... Yolken, R. H. (2010). Subunit and whole molecule specificity of the anti-bovine casein immune response in recent onset psychosis and schizophrenia. Schizophrenia Research, 118(1-3), 240-247. https://doi.org/10.1016/J.SCHRES.2009.12.030

Simeonova, D., Ivanovska, M., Murdjeva, M., Carvalho, A. F., \& Maes, M. (2018). Recognizing the Leaky Gut as a Trans-diagnostic Target for Neuroimmune Disorders Using Clinical Chemistry and Molecular Immunology Assays. Current Topics in Medicinal Chemistry, 18(19), 1641-1655. https://doi.org/10.2174/1568026618666181115100610

Siwek, M., Sowa-Kućma, M., Styczeń, K., Misztak, P., Nowak, R. J., Szewczyk, B., ... Maes, M. (2017). Associations of Serum Cytokine Receptor Levels with Melancholia, Staging of Illness, Depressive and Manic Phases, and Severity of Depression in Bipolar Disorder. Molecular Neurobiology, 54(8), 5883-5893. https://doi.org/10.1007/s12035-016-0124-8

Slyepchenko, A., Maes, M., Jacka, F. N., Köhler, C. A., Barichello, T., McIntyre, R. S., ... Carvalho, A. F. (2017). Gut Microbiota, Bacterial Translocation, and Interactions with Diet: Pathophysiological Links between Major Depressive Disorder and Non-Communicable Medical Comorbidities. Psychotherapy and Psychosomatics, 86(1), 31-46. https://doi.org/10.1159/000448957

Sowa-Kućma, M., Styczeń, K., Siwek, M., Misztak, P., Nowak, R. J., Dudek, D., .. Maes, M. (2018a). Are there differences in lipid peroxidation and immune biomarkers between major 
depression and bipolar disorder: Effects of melancholia, atypical depression, severity of illness, episode number, suicidal ideation and prior suicide attempts. Progress in NeuroPsychopharmacology and Biological Psychiatry, 81, 372-383.

https://doi.org/10.1016/j.pnpbp.2017.08.024

Sowa-Kućma, M., Styczeń, K., Siwek, M., Misztak, P., Nowak, R. J., Dudek, D., .. Maes, M. (2018b). Lipid Peroxidation and Immune Biomarkers Are Associated with Major Depression and Its Phenotypes, Including Treatment-Resistant Depression and Melancholia. Neurotoxicity Research, 33(2), 448-460. https://doi.org/10.1007/s12640-017-9835-5

Sudo, N., Chida, Y., Aiba, Y., Sonoda, J., Oyama, N., Yu, X.-N., ... Koga, Y. (2004). Postnatal microbial colonization programs the hypothalamic-pituitary-adrenal system for stress response in mice. The Journal of Physiology, 558(Pt 1), 263-275. https://doi.org/10.1113/jphysiol.2004.063388

Twigg, H. L. (2005). Humoral Immune Defense (Antibodies): Recent Advances. Proceedings of the American Thoracic Society, 2(5), 417-421. https://doi.org/10.1513/pats.200508-089JS Vojdani, A., \& Vojdani, E. (2019). Food-Associated Autoimmunities: When Food Breaks Your Immune System. First Edition, Autoimmunity, volume 1 (First Edit). A\&G Wilshire, LLC (June 1, 2019).

Wegner, A., Elsenbruch, S., Rebernik, L., Roderigo, T., Engelbrecht, E., Jäger, M., ... Benson, S. (2015). Inflammation-induced pain sensitization in men and women: does sex matter in experimental endotoxemia? Pain, 156(10), 1954.

https://doi.org/10.1097/J.PAIN.0000000000000256 
Table 1. Demographic and clinical data in healthy controls (HC), bipolar type I (BP1) and BP2 patients and unipolar major depressed (MDD) patients

\begin{tabular}{|c|c|c|c|c|c|c|c|}
\hline Variables & $\mathrm{HC}^{\mathrm{A}}$ & BP2 ${ }^{\text {B }}$ & BP1 $^{\mathrm{C}}$ & MDD $^{D}$ & $F / x^{2}$ & df & $\mathbf{P}$ \\
\hline Age (years) & $38.9(11.7)$ & $39.1(12.8)$ & $42.2(12.4)$ & $45.6(12.3)$ & 2.50 & $3 / 136$ & 0.062 \\
\hline $\operatorname{Sex}(\mathrm{F} / \mathrm{M})$ & $20 / 10$ & $24 / 13$ & $15 / 14$ & $21 / 23$ & 3.95 & 3 & 0.267 \\
\hline $\mathrm{ND}(\mathrm{Y} / \mathrm{N})$ & $28 / 1$ & $25 / 8$ & $24 / 5$ & $41 / 3$ & $\Psi=0.246$ & - & 0.043 \\
\hline TRD (N/Y) & - & $33 / 4^{\mathrm{D}}$ & $23 / 6$ & $29 / 15^{\mathrm{B}}$ & 6.70 & 2 & 0.043 \\
\hline Number episodes & - & $6.5(4.8)$ & $8.2(5.5)$ & $5.9(6.0)$ & 1.32 & $2 / 107$ & 0.273 \\
\hline Peroxides $(\mu \mathrm{mol} / \mathrm{L}) *$ & $239.2(136.3)^{\mathrm{D}}$ & $531.3(565.5)$ & $524.6(466.1)$ & $504.7(463.7)^{\mathrm{A}}$ & 1.51 & $3 / 68$ & 0.220 \\
\hline
\end{tabular}

Results are shown as mean (SD)

BMI: body mass index, ND: nicotine dependence, TRD: treatment resistant depression, HAM-D: total score on the Hamilton Depression Rating Scale

IgG oxidized LDL: IgG responses to oxidized low density lipoprotein

$A, B, C, D$ : Results of pairwise comparisons between the study groups 
Table 2. Results of multivariate GLM analyses with IgA responses to Gram-negative bacteria as dependent variables and diagnoses as explanatory variables

\begin{tabular}{|c|c|c|c|c|c|c|}
\hline Tests & Dependent variable & $\begin{array}{l}\text { Explanatory } \\
\text { variable }\end{array}$ & $\mathbf{F}$ & df & $\mathbf{P}$ & $\begin{array}{l}\text { Partial eta } \\
\text { squared }\end{array}$ \\
\hline Multivariate \#1 & All 6 IgA values & $\mathrm{HC} / \mathrm{BP} 1 / \mathrm{BP} 2 / \mathrm{MDD}$ & 1.74 & $18 / 393$ & 0.030 & 0.074 \\
\hline \multirow{6}{*}{$\begin{array}{l}\text { Between-subject } \\
\text { effects }\end{array}$} & Hafnia alvei & HC/BP1/BP2/MDD & 2.76 & $3 / 133$ & 0.045 & 0.058 \\
\hline & Pseudomonas aeruginosa & $\mathrm{HC} / \mathrm{BP} 1 / \mathrm{BP} 2 / \mathrm{MDD}$ & 2.63 & $3 / 133$ & 0.053 & 0.056 \\
\hline & Morganella morganii & HC/BP1/BP2/MDD & 3.66 & $3 / 133$ & 0.014 & 0.076 \\
\hline & Pseudomonas putida & HC/BP1/BP2/MDD & 2.76 & $3 / 133$ & 0.045 & 0.058 \\
\hline & Citrobacter koseri & HC/BP1/BP2/MDD & 3.57 & $3 / 133$ & 0.016 & 0.074 \\
\hline & Klebsiella pneumoniae & HC/BP1/BP2/MDD & 3.72 & $3 / 133$ & 0.013 & 0.077 \\
\hline Tests & Dependent variable & Explanatory variable & $\mathbf{F}$ & df & $\mathbf{P}$ & $\begin{array}{l}\text { Partial eta } \\
\text { squared }\end{array}$ \\
\hline Multivariate \#2 & All 6 IgA values & HC/No-MEL/MEL & 4.31 & $12 / 262$ & $<0.001$ & 0.165 \\
\hline \multirow{6}{*}{$\begin{array}{l}\text { Between-subject } \\
\text { effects }\end{array}$} & H. alvei & HC/ No-MEL/MEL & 4.48 & $2 / 135$ & 0.013 & 0.062 \\
\hline & P. aeruginosa & HC/ No-MEL/MEL & 3.17 & $2 / 135$ & 0.045 & 0.045 \\
\hline & M. morganii & HC/ No-MEL/MEL & 6.52 & $2 / 135$ & 0.002 & 0.088 \\
\hline & P.putida & HC/ No-MEL/MEL & 4.31 & $2 / 135$ & 0.015 & 0.060 \\
\hline & C. koseri & HC/ No-MEL/MEL & 13.42 & $2 / 135$ & $<0.001$ & 0.166 \\
\hline & K. pneumoniae & HC/ No-MEL/MEL & 8.74 & $2 / 135$ & $<0.001$ & 0.115 \\
\hline
\end{tabular}

HC/BP2/BP1/MDD: heathy controls, bipolar disorder type 2 (BP2), type 1 (BP1) and unipolar major depression (MDD) No-MEL/MEL: patients with BP1/BP2/MDD with (MEL) and without (No-MEL) melancholia 
Table 3. Estimated marginal mean values (in z scores, SE) of the $\operatorname{IgA}$ and $\operatorname{IgM}$ responses to Gram-negative bacteria

\begin{tabular}{|c|c|c|c|c|c|c|c|}
\hline $\begin{array}{l}\text { IgA } \\
\text { responses }\end{array}$ & $\mathrm{HC}^{\mathrm{A}}$ & BP2 ${ }^{\text {B }}$ & BP1 C & MDD $^{D}$ & $\mathrm{HC}^{\mathrm{A}}$ & No-MEL ${ }^{B}$ & MEL $^{c}$ \\
\hline Hafnia alvei* & $-0.395(0.179)^{\mathrm{C}, \mathrm{D}}$ & $-0.058(0.161)$ & $0.296(0.179)^{\mathrm{A}}$ & $0.119(0.147)^{\mathrm{A}}$ & $-0.406(0.181)^{\mathrm{B}, \mathrm{C}}$ & $0.047(0.098)^{\mathrm{A}}$ & $0.488(0.250)^{\mathrm{A}}$ \\
\hline $\begin{array}{l}\text { Pseudomonas } \\
\text { aeruginosa* }\end{array}$ & $-0.419(0.188)^{\mathrm{B}, \mathrm{C}, \mathrm{D}}$ & $0.067(0.162)^{\mathrm{A}}$ & $0.250(0.180)^{\mathrm{A}}$ & $0.085(0.148)^{\mathrm{A}}$ & $-0.401(0.183)^{\mathrm{B}}$ & $0.117(0.099)^{\mathrm{A}}$ & $0.096(0.253)$ \\
\hline $\begin{array}{l}\text { Morganella } \\
\text { morganii* }\end{array}$ & $-0.435(0.100)^{\mathrm{C}, \mathrm{D}}$ & $-0.047(0.162)$ & $0.393(0.180)^{\mathrm{A}}$ & $0.091(0.148)^{\mathrm{A}}$ & $-0.413(0.181)^{\mathrm{B}, \mathrm{C}}$ & $0.023(0.098)^{\mathrm{A}, \mathrm{C}}$ & $0.706(0.250)^{\mathrm{A}, \mathrm{B}}$ \\
\hline $\begin{array}{l}\text { Pseudomonas } \\
\text { putida* }\end{array}$ & $-0.264(0.182)^{\mathrm{C}}$ & $-0.063(0.164)^{\mathrm{C}}$ & $0.443\left(0.182^{\mathrm{A}, \mathrm{B}, \mathrm{D}}\right.$ & $-0.046(0.150)^{\mathrm{C}}$ & $-0.251(0.184)^{\mathrm{C}}$ & $-0.021(0.100)^{\mathrm{C}}$ & $0.665(0.254)^{\mathrm{A}, \mathrm{B}}$ \\
\hline $\begin{array}{l}\text { Citrobacter } \\
\text { koseri* }^{*}\end{array}$ & $-0.202(0.178)^{\mathrm{C}}$ & $-0.231(0.100)^{\mathrm{C}}$ & $0.484(0.177)^{\mathrm{A}, \mathrm{B}, \mathrm{D}}$ & $-0.10(0.146)^{\mathrm{C}}$ & $-0.209(0.171)^{\mathrm{C}}$ & $-0.124(0.093)^{\mathrm{C}}$ & $1.149(0.236)^{\mathrm{A}, \mathrm{B}}$ \\
\hline $\begin{array}{l}\text { Klebsiella } \\
\text { pneumonia* }\end{array}$ & $-0.439(0.178)^{\mathrm{C}}$ & $0.009(0.160)$ & $0.397(0.177)^{\mathrm{A}}$ & $-0.029(0.146)$ & $-0.452(0.176)^{\mathrm{B}, \mathrm{C}}$ & $0.017(0.095)^{\mathrm{A}, \mathrm{C}}$ & $0.814(0.293)^{\mathrm{A}, \mathrm{B}}$ \\
\hline $\begin{array}{l}\text { IgM } \\
\text { responses }\end{array}$ & $\mathrm{HC}^{\mathrm{A}}$ & BP2 ${ }^{\text {B }}$ & BP1 C & MDD $^{D}$ & $\mathrm{HC}^{\mathrm{A}}$ & No-MEL ${ }^{\text {B }}$ & MEL $^{c}$ \\
\hline H. alvei & $-0.504(0.176)^{\mathrm{C}, \mathrm{D}}$ & $-0.275(0.159)^{\mathrm{C}, \mathrm{D}}$ & $0.351(0.176)^{\mathrm{A}, \mathrm{B}}$ & $0.332(0.145)^{\mathrm{A}, \mathrm{B}}$ & $-0.472(0.185)^{\mathrm{B}}$ & $0.127(0.100)^{\mathrm{A}}$ & $0.116(0.256)$ \\
\hline P. aeruginosa & $-0.672(0.174)^{\mathrm{B}, \mathrm{C}, \mathrm{D}}$ & $0.052(0.157)^{\mathrm{A}}$ & $0.289(0.174)^{\mathrm{A}}$ & $0.226(0.143)^{\mathrm{A}}$ & $-0.654(0.177)^{\mathrm{B}, \mathrm{C}}$ & $0.208(0.096)^{\mathrm{A}}$ & $-0.040(2.45)^{\mathrm{A}}$ \\
\hline M. morganii & $-0.525(0.172)^{\mathrm{C}, \mathrm{D}}$ & $-0.234(0.155)^{\mathrm{C}}$ & $0.584(0.172)^{\mathrm{A}, \mathrm{B}}$ & $0.152(0.142)^{\mathrm{A}}$ & $-0.486(0.183)^{\mathrm{B}, \mathrm{C}}$ & $0.114(0.099)^{\mathrm{A}}$ & $0.201(0.253)^{\mathrm{A}}$ \\
\hline P. putida & $-0.688(0.173)^{\mathrm{B}, \mathrm{C}, \mathrm{D}}$ & $-0.057(0.156)^{\mathrm{A}}$ & $0.343(0.173)^{\mathrm{A}}$ & $0.227(0.142)^{\mathrm{A}}$ & $-0.648(0.179)^{\mathrm{B}, \mathrm{C}}$ & $0.159(0.097)^{\mathrm{A}}$ & $0.077(0.247)^{\mathrm{A}}$ \\
\hline C. koseri & $-0.408(0.180)^{\mathrm{C}, \mathrm{D}}$ & $-0.226(0.162)^{\mathrm{C}}$ & $0.386(0.180)^{\mathrm{A}, \mathrm{B}}$ & $0.194(0.148)^{\mathrm{A}}$ & $-0.384(0.187)$ & $0.111(0.102)$ & $0.014(0.259)$ \\
\hline K. pneumoniae & $-0.319(0.182)^{\mathrm{C}}$ & $0.040(0.164)$ & $0.258(0.182)^{\mathrm{A}}$ & $-0.044(0.150)$ & $-0.314(0.186)$ & $0.029(0.101)$ & $0.256(0.256)$ \\
\hline Sum 12 IgA/IgM & $-0.705(0.170)^{\mathrm{B}, \mathrm{C}, \mathrm{D}}$ & $-0.136(0.153)^{\mathrm{A}, \mathrm{C}}$ & $0.602(0.170)^{\mathrm{A}, \mathrm{B}}$ & $0.171(0.140)^{\mathrm{A}}$ & $-0.682(0.178)^{\mathrm{B}, \mathrm{C}}$ & $0.101(0.096)^{\mathrm{A}, \mathrm{C}}$ & $0.626(0.245)^{\mathrm{A}, \mathrm{B}}$ \\
\hline
\end{tabular}

HC/BP2/BP1/MDD: heathy controls, bipolar disorder type 2 (BP2), type 1 (BP1) and unipolar major depression (MDD)

No-MEL/MEL: patients with BP1/BP2/MDD with (MEL) and without (No-MEL) melancholia

$\mathrm{A}, \mathrm{B}, \mathrm{C}, \mathrm{D}$ : Results of pairwise comparisons between the study groups

Sum 12 IgA/IgM: integrated index of bacterial translocation computed as z (sum of $\mathrm{z}$ values of $\operatorname{Ln}$ IgM to the 6 Gram-negative bacteria + sum of $z$ values of $\operatorname{Ln} \operatorname{IgA}$ to the 6 Gram-negative bacteria). 
Table 4. Results of multivariate GLM analyses with IgM responses to Gram-negative bacteria as dependent variables

\begin{tabular}{|c|c|c|c|c|c|c|}
\hline Tests & Dependent variables & Explanatory variables & $\mathbf{F}$ & df & $\mathbf{P}$ & $\begin{array}{l}\text { Partial eta } \\
\text { squared }\end{array}$ \\
\hline Multivariate \#1 & All 6 IgM values & $\mathrm{HC} / \mathrm{BP} 2 / \mathrm{BP} 1 / \mathrm{MDD}$ & 3.01 & $18 / 393$ & $<0.001$ & 0.121 \\
\hline \multirow{6}{*}{$\begin{array}{l}\text { Between- } \\
\text { subject effects }\end{array}$} & Hafnia alvei & $\mathrm{HC} / \mathrm{BP} 2 / \mathrm{BP} 1 / \mathrm{MDD}$ & 6.53 & $3 / 134$ & $<0.001$ & 0.127 \\
\hline & $\begin{array}{l}\text { Pseudomonas } \\
\text { aeruginosa }\end{array}$ & HC/BP2/BP1/MDD & 6.72 & $3 / 134$ & $<0.001$ & 0.131 \\
\hline & Morganella morganii & $\mathrm{HC} / \mathrm{BP} 2 / \mathrm{BP} 1 / \mathrm{MDD}$ & 7.90 & $3 / 134$ & $<0.001$ & 0.150 \\
\hline & Pseudomonas putida & HC/BP2/BP1/MDD & 7.36 & $3 / 134$ & $<0.001$ & 0.141 \\
\hline & Citrobacter koseri & HC/BP2/BP1/MDD & 4.31 & $3 / 134$ & 0.006 & 0.088 \\
\hline & Klebsiella pneumoniae & $\mathrm{HC} / \mathrm{BP} 2 / \mathrm{BP} 1 / \mathrm{MDD}$ & 1.75 & $3 / 134$ & 0.161 & 0.038 \\
\hline Multivariate \#2 & All 6 IgM values & HC/No-MEL/MEL & 2.12 & $12 / 262$ & 0.016 & 0.089 \\
\hline \multirow{6}{*}{$\begin{array}{l}\text { Between- } \\
\text { subject effects }\end{array}$} & Hafnia alvei & HC/No-MEL/MEL & 4.16 & $2 / 135$ & 0.018 & 0.058 \\
\hline & $\begin{array}{l}\text { Pseudomonas } \\
\text { aeruginosa }\end{array}$ & HC/No-MEL/MEL & 9.30 & $2 / 135$ & $<0.001$ & 0.121 \\
\hline & Morganella morganii & HC/No-MEL/MEL & 4.50 & $2 / 135$ & 0.013 & 0.062 \\
\hline & Pseudomonas putida & HC/No-MEL/MEL & 8.03 & $2 / 135$ & 0.001 & 0.106 \\
\hline & Citrobacter koseri & HC/No-MEL/MEL & 2.72 & $2 / 135$ & 0.069 & 0.039 \\
\hline & Klebsiella pneumoniae & HC/No-MEL/MEL & 1.93 & $2 / 135$ & 0.149 & 0.028 \\
\hline Univariate \#3 & Sum $12 \operatorname{IgA} / \operatorname{IgM}$ & HC/BP1/BP2/MDD & 10.49 & $3 / 34$ & $<0.001$ & 0.190 \\
\hline Univariate \#4 & Sum $12 \operatorname{IgA} / \operatorname{IgM}$ & HC/No-MEL/MEL & 11.05 & $2 / 135$ & $<0.001$ & 0.141 \\
\hline
\end{tabular}

HC/BP2/BP1/MDD: heathy controls, bipolar disorder type 2 (BP2), type 1 (BP1) and unipolar major depression (MDD) No-MEL/MEL: patients with BP1/BP2/MDD with (MEL) and without (No-MEL) melancholia

Sum 12 IgA/IgM: integrated index of bacterial translocation computed as z (sum of z values of Ln IgM to the 6 Gram-negative bacteria + sum of $\mathrm{z}$ values of $\operatorname{Ln} \operatorname{IgA}$ to the 6 Gram-negative bacteria). 
Table 5. Results of binary and multinomial logistic regression analyses with IgA responses to Gram-negative bacteria as explanatory variables and diagnosis as dependent variable.

\begin{tabular}{|c|c|c|c|c|c|c|c|c|}
\hline Binary & Explanatory variables & B & SE & $\mathbf{W}$ & df & $\mathbf{p}$ & OR & CI $95 \%$ \\
\hline \multirow[t]{2}{*}{ Mood vs HCs } & $\begin{array}{l}\text { IgA Pseudomonas } \\
\text { aeruginosa }\end{array}$ & 1.093 & 0.378 & 8.34 & 1 & 0.004 & 2.98 & $1.42-6.26$ \\
\hline & IgM $P$. aeruginosa & 1.131 & 0.313 & 13.05 & 1 & $<0.001$ & 3.10 & $1.68-5.73$ \\
\hline \multicolumn{9}{|l|}{ Multinomial \#1 } \\
\hline \multirow[t]{2}{*}{ BP2 vs HCs } & IgA Morganella morganii & 0.837 & 0.418 & 4.01 & 1 & 0.045 & 2.31 & $1.02-5.25$ \\
\hline & IgM $P$. aeruginosa & 1.405 & 0.478 & 8.63 & 1 & 0.003 & 4.08 & $1.60-10.41$ \\
\hline BP1 vs HCs & IgA M. morganii & 1.294 & 0.431 & 9.01 & 1 & 0.003 & 3.65 & $1.57-8.49$ \\
\hline \multirow[t]{2}{*}{ MDD vs HCs } & IgA M. morganii & 1.016 & 0.415 & 6.00 & 1 & 0.014 & 2.76 & $1.23-6.23$ \\
\hline & IgM $P$. aeruginosa & 0.241 & 0.478 & 6.74 & 1 & 0.009 & 3.46 & $1.36-8.82$ \\
\hline BP1 vs BP2 & IgM M. morganii & 1.333 & 0.405 & 10.84 & 1 & 0.001 & 3.79 & $1.72-8.39$ \\
\hline BP1 vs MDD & IgM M. morganii & 0.724 & 0.347 & 4.37 & 1 & 0.037 & 2.06 & $1.05-4.07$ \\
\hline \multicolumn{9}{|l|}{ Multinomial \#2 } \\
\hline MEL vs HCs & IgA Citrobacter koseri & 1.323 & 0.526 & 6.34 & 1 & 0.012 & 3.76 & $1.34-10.52$ \\
\hline \multirow[t]{2}{*}{ No-MEL vs HCs } & $\operatorname{IgA} P$. aeruginosa & 1.155 & 0.453 & 6.51 & 1 & 0.011 & 3.17 & $1.31-7.71$ \\
\hline & IgM $P$. aeruginosa & 1.074 & 0.309 & 12.07 & 1 & 0.001 & 2.93 & $1.60-5.37$ \\
\hline MEL vs No-MEL & IgA C. koseri & 1.594 & 0.436 & 13.36 & 1 & $<0.001$ & 4.92 & $2.09-11.57$ \\
\hline
\end{tabular}

HC/BP2/BP1/MDD: heathy controls, bipolar disorder type 2 (BP2), type 1 (BP1) and unipolar major depression (MDD)

No-MEL/MEL: patients with BP1/BP2/MDD with (MEL) and without (No-MEL) melancholia

MOOD: BP2 + BP1 + MDD 
Table 6. Results of multiple regression analyses with severity of depression and oxidative stress biomarkers as dependent variables and $\operatorname{IgA} / \operatorname{IgM}$ responses to Gram-negative bacteria and demographic data as explanatory variables

\begin{tabular}{|l|l|l|l|l|l|l|l|l|l|}
\hline $\begin{array}{l}\text { Dependent } \\
\text { variables }\end{array}$ & Explanatory Variables & $\mathbf{B}$ & SE & $\mathbf{F}$ & $\mathbf{p}$ & $\mathbf{F}$ model & $\mathbf{d f}$ & $\mathbf{p}$ & $\mathbf{R}^{\mathbf{2}}$ \\
\hline HAM-D & IgA Citrobacter koseri & 1.022 & 0.224 & 4.56 & $<0.001$ & 16.78 & $2 / 107$ & $<0.001$ & 0.239 \\
\cline { 2 - 9 } & Age & 0.045 & 0.019 & 2.33 & 0.022 & & & & \\
\hline \multirow{2}{*}{$\begin{array}{l}\text { IgG oxidized } \\
\text { LDL }\end{array}$} & $\begin{array}{l}\text { IgM Pseudomonas } \\
\text { aeruginosa }\end{array}$ & 0.0352 & 0.108 & 3.25 & 0.002 & 8.52 & $2 / 73$ & $<0.001$ & 0.189 \\
\cline { 2 - 9 } & IgA Hafnei alvei & 0.204 & 0.096 & 2.12 & 0.038 & & & & \\
\hline
\end{tabular}

HAM-D: total score on the Hamilton Depression Rating Scale

IgG oxidized LDL: IgG responses to oxidized low density lipoprotein 